urea also indicate marked nitrogen retention in animals dying from oxperimentally induced 'pregnancy toxæmia'.

The reason for the discrepaney between our results for creatine and those of Blanch and Setchell is not clear. It seems possible that the ewes used by the latter workers may have been non-pregnant-in our study animals of this type showed comparatively little change in plasma creatine after six days starvation (the period used by Blanch and Setchell) in contrast to the larger changes seen in pregnant animals. Of possible significance also is the observation that in the pregnant sheep plasma creatine-levels tended to be lower on the sixth day than on the fourth, ninth or eleventh days of the fast. A possible difference in specificity of the method used for creatine in our work would also account for the discrepancy but is believed to be rather unlikely.

We thank Messrs. Imperial Chemical Industries, Ltd., for a grant in support of these experiments.

$$
\text { P. J. Pearce }
$$

J. S. S. INGLIS

Department of Animal Husbandry

and Veterinary Preventive Medicine,

University of Glasgow Veterinary Hospital, Bearsden, Glasgow.

2 Blanch, E., and Setchell, B. P., A ustral. J. Biol. Sci., 13, 356 (1960) ${ }^{2}$ Fraser, A. H. H., Godden, W., Snook, L. C., and Thomson, W. J. Physiol., 94, 346 (1958).

'Groenewald, J. W., Graf, H., Bekker, P. M., Malan, J. R., and Clark, R., Onderstepoort $J$. Vet. Sci., 17, 245 (1941).

- Parry, H. B., and Taylor, W. H., J. Physiol., 131, 383 (1956).

- Reid, R. L., Austral. J. Agric. Res., 11, 346 (1960).

\section{Sea Salt and Dental Caries}

ExPERIENCE in the United States and elsewhere has shown that the main source for the fluoride intake in man for the partial prevention of dental caries is the water supply. Results from recent investigations in India and Greece strongly suggest that the daily consumption of sea salt by the people of these countries may have been another major source of dietary fluoride. Sea salt was reported to contain 40 p.p.m. of fluoride ${ }^{1}$. The fluoride content of teeth from India and Greece was found to be considerably high although the level in the water supplies was negligible ${ }^{1,2}$. In addition, the prevalence of caries in the two countries has been reported to be low ${ }^{1,3}$.

It is generally believed that children up to 12 years of age consuming water containing continuously about 1.0 p.p.m. of fluoride will ingest from water alone approximately $0.4-1.0 \mathrm{mgm}$. of fluoride daily; amounts which will provide considerable protection against caries. In order to ingest these levels of fluoride entirely from sea salt, containing $40 \mathrm{p} . \mathrm{p.m}$. of fluoride, a daily intake of about $10-25 \mathrm{gm}$. would be required. However, significant reduction in caries has been also observed in children using water alternating in its natural fluoride content from day to day between $0 \cdot 2$ and $1 \cdot 0$ p.p.m. ${ }^{4}$. It thus seems likely that intermittent ingestion of sea salt in amounts comparable with the above-mentioned may also result in a fluoride intake sufficient to provide considerable protection against caries.

The ingestion of high amounts of salt is not unlikely among people of certain countries because of their dietary habits and food customs. It has been reported that the ration of the armed forces of the Republic of Korea included $30 \mathrm{gm}$. of crude sea salt per man per day ${ }^{5}$. Furthermore, up to twice this amount was ingested daily from the consumption of native food preparations containing high amounts of sea salt ${ }^{5}$. In this connexion, it may be significant that susceptibility to caries among the men of the armed forces was found to be very low ${ }^{5}$. In a nutritional survey of the armed forces of Iran it was shown that an allowance of about $30 \mathrm{gm}$. of salt per man per day, obtained from mines, was included in the menu ${ }^{6}$. The amount of sea salt produced by salterns in Greece annually indicates that the daily ingestion by the population may be considerable ${ }^{7}$. In addition, experiments with laboratory animals indicated that increasing the calcium-level in the diet decreased the amount of fluoride absorbed from the intestinal tract ${ }^{8}$. Therefore, in countries where the level of calcium intake is low there may be an increase in the absorption of the ingested fluoride; thus a smaller amount of dietary fluoride would be required daily for protection against caries.

In conclusion, it is proposed that serious consideration should be given to the role of sea salt as an important source of dietary fluoride for the prevention of dental caries in areas of the world where the salt consumed locally is prepared by evaporating sea water.

D. M. Hadjimarkos

University of Oregon Dental School, Portland, Oregon.

${ }^{1}$ Shaw, J. H., et al., Amer. J. Clin, Nutrit., 4, 246 (1956).

${ }^{2}$ Hadjimarkos, D. M., and Bonhorst, C. W., Nature, 193, 177 (1962)

${ }^{3}$ Hadjimarkos, D. M., J. Dent. Res., 39, 590 (1960).

4 Bruce, H. W., and Gunter, B. F., J. Dent. Res., 32, 35 (1953).

${ }^{5}$ Williams, R. R., et al., J. Nutrit., 68 (Supp. No. 1), 1 (1959).

${ }^{6}$ Browe, J. H., et al., Amer. J. Clin. Nutrit., 9, 478 (1961).

7 Statistical Yearbook of Greece, 1959-60 (National Statistical Service, Athens).

${ }^{8}$ Largent, E. J., Fluoridation as a Public Health Measure, edit. by Shaw, J. H., 49 (Amer. Assoc. Adv. Sci., Washington, D.C. 1954).

\section{Spontaneous Hydronephrosis in Albino Rats}

DURING the course of an investigation on the influence of the pituitary gland on compensatory renal hypertrophy in rats' ${ }^{1}$, a surprisingly high incidence of hydronephrosis was encountered. This made it necessary to discard a great number of animals. The failure to find any reference to spontaneous hydronephrosis in rats in the literature has prompted this preliminary report ${ }^{2-6}$.

Table 1. SUMmary OF DATA ON INCrOFNCE OF HYDRONEPHROSIS IN \begin{tabular}{cccc} 
& \multicolumn{2}{c}{ ALBiNo RATS } & \\
Sex & No. of rats & $\begin{array}{c}\text { No. of rats with } \\
\text { hydronephrosis }\end{array}$ & $\begin{array}{c}\text { Percentage of } \\
\text { hydronephrosis }\end{array}$ \\
Male & 415 & 104 & 26.3
\end{tabular}

$\begin{array}{llrr}\text { Male } & 415 & 104 & 26 \cdot 3 \\ \text { Female } & 371 & 6 & 1 \cdot 6\end{array}$

Autopsy findings on 786 rats are presented in Table 1. The rats, which were apparently healthy, were killed because they served as controls in certain experiment or they had to be replaced by younger rats for the maintenance of the colony in the Unit. Only kidneys showing gross dilatation of the pelves and calices were considered to be hydronephrotic. A careful search for calculi in the urinary passages (pelvis, ureter and bladder) was carried out but none was found. Hydronephrosis was almost entirely confined to the right kidney and was much commoner in the male. The age of the rats (judged by the bodyweight) did not seem to affect the incidence of hydronephrosis.

The following findings in two rats is of exceptional interest. In one the right kidney was completely 